Int. J. Curr. Res. Med. Sci. (2017). 3(1): 7-14

OP

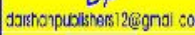

It

DARSHAN

PUBLISHERS

wan.darshamo.bishers.con
International Journal of Current Research in Medical Sciences

ISSN: 2454-5716

WWw.ijcrims.com

Volume 3, Issue 1 -2017

\title{
"Insidious Spontaneous Complete Uterine Rupture in a 17-Week Primigravida with a Rudimentary Hemi-Uterus: A Case Report and Literature Review"
}

\author{
Samantha Mc Kenzie Stancu MD ${ }^{1}$, Dragos Stefan Dobritoiu MD, PhD ${ }^{2}$, \\ Manuela Russu MD, PhD ${ }^{1,2}$ \\ 1 “Carol Davila” University of Medicine \& Pharmacy, 37 Dionisie Lupu Street, District 1, Bucharest, \\ Romania 020021 \\ 2 “Dr. I. Cantacuzino” Clinical Hospital, Bucharest, Romania, Discipline of Obstetrics and Gynaecology, \\ 5-7 Ion Movila Street, District 2, Bucharest, Romania 020475, \\ ${ }^{1,2}$ Professor of Obstetrics and Gynecology \\ Corresponding author: Samantha Mc Kenzie Stancu \\ 24 Hagi Ghita Street, District 1, Bucharest, Romania 011503, Tel: + 40757221330 , \\ E-mail: samantha.mckenzie730@gmail.com
}

\begin{abstract}
M.N., a 21-year old female patient presented to the emergency room with a one-day history of lower abdominal pain and signs of hypovolaemic shock. The patient had underwent a dilatation and curettage (D\&C) 11 weeks prior for elective pregnancy termination at another facility. Transvaginal ultrasound revealed a well-circumscribed anechoic collection measuring 10/16 centimeters in diameter in the Douglas pouch and a pregnant uterus carrying a 17-week fetus with cardiac activity. Upon emergency laparotomy, 1500 milliliters of blood were found, as well as a blackviolet-colored rudimentary hemi-uterus, covered with clots. Upon gentle maneuvers to remove the clots from the left hemi-uterine surface, spontaneous complete uterine rupture ensued with exteriorisation of a 17-centimeter fetus into the peritoneal cavity. Resistance was encountered upon attempt to detach the placenta, and upon a closer look, placenta accreta was diagnosed. Consequently, the left rudimentary hemi-uterus was excised with a hemihysterectomy. The patient's postoperative follow-up was uneventful and her prognosis is favorable from the perspective of fertility-conserving surgery. This is the third case reported in the world and the second case published since the new millennium of spontaneous complete uterine rupture during the second trimester in a primigravida with a rudimentary hemi-uterus.
\end{abstract}

Keywords: complete rupture of the unscarred uterus, haemoperitoneum, second trimester, primigravida, rudimentary hemi-uterus, congenital uterine anomaly. 


\section{Introduction}

Uterine rupture is a catastrophic obstetric complication associated with astonishingly high rates of fetal and maternal morbidity and mortality reaching 80-95\% (Hofmeyr et al., 2005). Complete uterine rupture is defined as the loss of discontinuity between the uterine and peritoneal cavities, resulting in the expulsion of the fetus into the latter (Walsh et al., 2007). Uterine ruptures are classified according to aetiology as either traumatic or spontaneous. Traumatic ruptures occur as a result of obstetric manoeuvres including induction of labour and augmented labour or non-obstetric violent trauma (Landon, 2006).

Spontaneous rupture of the unscarred uterus is an exceedingly rare entity, with an incidence ranging from 1 in 16,840-19,765 cases in the developed world (Landon, 2006, Gardeil et al., 1994). The vast majority of primary complete uterine ruptures occur during labour or the third trimester. Literature reveals a paucity of complete primary uterine rupture during the secondary trimester, with evidence limited to case reports. As such, no risk factors have been established for complete ruptures occurring earlier than the third trimester (Zwart et al., 2009).

Risk factors for uterine rupture in the third trimester and during labour include previous Caesarean Section $(\mathrm{C} / \mathrm{S})$, previous uterine surgery with hysterotomy, multiparity, morbidly adherent placenta, multiple pregnancy, malpresentation, obstetric manoeuvres including instrumental delivery, external cephalic version and internal podalic version, curettage, congenital uterine anomaly, augmented labour, induction of labour and connective tissue disorders (Hofmeyr et al., 2005, Walsh et al., 2007, Al-Zirqi et al., 2016, Haidar et al., 2016, Sivanesan et al., 2010, Oral et al., 2001, Palacios-Jaraquemada et al., 2009, Gibbins et al., 2015, Ofir et al., 2003, Thisted et al., 2015, Tola, 2014, Shirata et al., 2007, Pepin et al., 2000, Hagnere et al., 2011).

Currently, there are no precise diagnostic criteria for uterine rupture during pregnancy and labour (Hofmeyr et al., 2005, Abdalla et al., 2015). Not only is uterine rupture an extraordinarily rare occurrence, but its clinical presentation is also non-specific, exposing both the mother and fetus to life-threatening compromise (Hofmeyr et al., 2005, Gueye et al., 2015, Kabra et al., 2016). Most frequently, complete uterine rupture presents with sudden onset abdominal pain, cessation of uterine contractions, vaginal bleeding, signs of hypovolaemic shock (Walsh et al., 2007,
Vernekar and Rajib, 2015, Yap et al., 2001). The lack of specific symptomatology suggests why diagnosis is often delayed, resulting in maternal compromise and fetal jeopardy (Al-Zirqi et al., 2016, Surico et al., 2016).

The only method capable of ensuring a correct diagnosis of complete uterine rupture is emergency laparoscopy or laparotomy (Mazzone and Woolever, 2006). There is a vast array of differential diagnoses to be considered for uterine rupture including other types of antepartum haemorrhage (placental abruption, vasa praevia, placenta praevia), acute abdomen, coagulopathy, uterine artery rupture and other causes of haemoperitoneum (Walsh et al., 2007, Mazzone and Woolever, 2006, Sun et al., 2012).

The treatment options for complete uterine rupture depend on gestational age and consist of either delivery via $\mathrm{C} / \mathrm{S}$ or repair of the defect enabling pregnancy continuation. The defect is first repaired with a double or triple layer of sutures, then additional methods of sealing the defect may be employed such as the application of a mesh, omental patch, fibrincoated collagen fleece patch or absorbable haemostatic powder (Haidar et al., 2016, Palacios-Jaraquemada et al., 2009, Shirata et al., 2007, Abdalla et al., 2015, Surico et al., 2016, Sun et al., 2012, Sugawara et al., 2014). In the event of a rupture that has produced damage beyond repair, or uncontrollable haemorrhage, an obstetric hysterectomy is the procedure of last resort (Hofmeyr et al., 2005, Walsh et al., 2007, Landon, 2006, Gibbins et al., 2015, Tola, 2014, Gueye et al., 2012).

This article recounts the case of an insidious spontaneous complete uterine rupture in a 17-week primigravida with a rudimentary hemi-uterus. To the authors' knowledge, this is the third case in the world and the second case published since the new millennium of primary complete uterine rupture during the second trimester in a primigravida with a rudimentary hemi-uterus.

\section{Case Presentation}

M.N., a 21-year old female patient presented to the emergency room on the morning of December $6^{\text {th }}$, 2015 with a one-day history of lower abdominal pain accompanied by a single episode of nausea and vomiting and signs of hypovolaemic shock. The patient's social history consisted of residing in a rural setting and being unemployed. She denied abdominal trauma or vaginal bleeding. Her obstetric history consisted of a dilation and curettage (D\&C) for 
elective pregnancy termination at 6 weeks gestation, 11 weeks prior to presentation, at another facility. Her gynaecologic history featured a late-onset menarche, at age 17, followed by irregular menstrual cycles until present. Physical examination revealed a normoponderal (BMI: $\left.20.3 \mathrm{~kg} / \mathrm{m}^{2}\right)$, afebrile $\left(36^{\circ} \mathrm{C}\right)$ and pale patient. Her haemodynamic assessment was consistent with haemodynamic shock (blood pressure: 90/60 $\mathrm{mmHg}$, heart rate: 156 beats per minute and respiratory rate: 25 respirations per minute).

On abdominal examination, distention was consistent with a 17-week pregnancy. The patient's inferior abdominal pain was exacerbated upon palpation. Abnormal abdominal dullness was noticed in the hypogastric region. Next, the patient underwent a valve and bimanual pelvic examination. The valve exam displayed a moderate amount of leukorrhea. There was no evidence of vaginal bleeding at the moment of the examination. Her cervix was closed, firm and posterior. On bimanual pelvic examination, uterine size was consistent with a 17-week pregnancy, the consistency was firm, however the shape was irregular.

A complete blood count exhibited leukocytosis $(17.500 / \mu \mathrm{L})$ with neutrophilia $(94 \%)$, anaemia (erythrocytes: 2.4 million $/ \mu \mathrm{L}$, haemoglobin: $7.2 \mathrm{mg} / \mathrm{dl}$, hematocrit: $23.3 \%)$, hyperglycaemia $(160 \mathrm{mg} / \mathrm{dl})$ and hyponatraemia $(130 \quad \mathrm{mEq} / \mathrm{L})$. Transvaginal ultrasonography revealed the aspect of two separate uterine cavities with a single cervix without funneling, although the exact aspect was difficult to identify. A well-circumscribed anechoic collection measuring $10 / 16$ centimeters $(\mathrm{cm})$ in diameter was discovered in the Douglas pouch, as depicted in Figure 1. Transabdominal ultrasonography revealed a single intrauterine pregnancy with a gestational age according to the last menstrual period of $16+6$ weeks and an ultrasound gestational age of $17+3$ weeks. The estimated fetal weight was $182 \pm 27$ grams. Fetal movements were visible and a reassuring fetal heart rate of 145 beats per minute was recorded. The quantity of liquor was normal and the placenta was located on the anterior uterine wall.

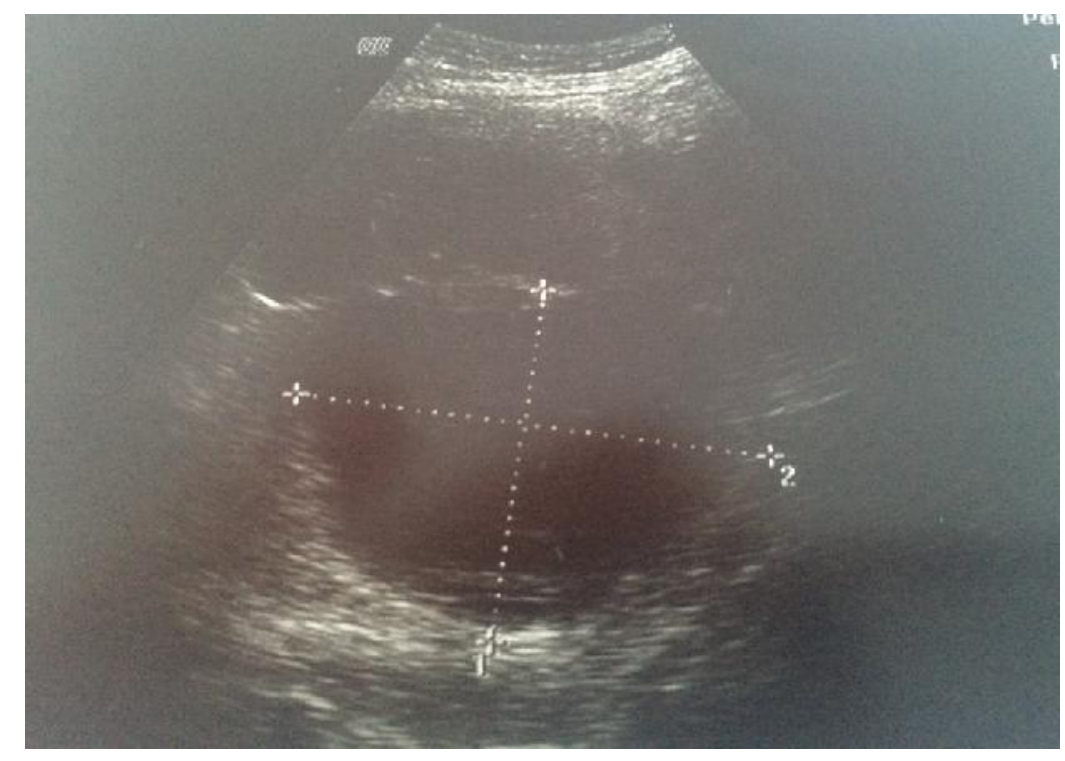

Figure 1: Anechoic collection measuring 10/16 cm in the Douglas pouch

The preliminary diagnosis was haemoperitoneum, evidenced by the collection and haemodynamic instability, prompting an emergency laparotomy. Prior to laparotomy, the patient was informed of the potential risks and benefits for both herself and the fetus, and she gave informed consent. Access into the peritoneal cavity was gained through a left-sided paramedian pubo-umbilical incision. Upon entrance into the peritoneal cavity, frank haemoperitoneum of 1500 milliliters (mL) was found, as well as a blackviolet-colored rudimentary hemi-uterus, covered with clots. There was a visible perforation located on the fundus of a rudimentary left hemi-uterus leaking fresh blood. Upon a gentle attempt to remove the blood clots from the hemi-uterine surface, complete uterine rupture ensued in real-time, resulting in the exteriorisation of a $17-\mathrm{cm}$ fetus into the peritoneal cavity. Resistance was encountered upon attempt to detach the placenta, and upon a closer look, placenta accreta was diagnosed. The unique ultrasonographic appearance of the uterus was elucidated upon visual inspection as a rudimentary hemi-uterus with two 
separate fundi and two cavities. The right hemi-uterus and annexae had a normal aspect, however the left hemi-uterus, which previously contained the fetus, was damaged beyond repair. A hemi-hysterectomy of the left hemi-uterus was performed in conjunction with haemostasis. Next, the right hemi-uterine cavity was evacuated via curette. Specimens were taken from the left hemi-uterus and placenta for histopathological analysis. Lavage of the peritoneal cavity was performed and the anatomical planes of the abdominal wall were approximated, culminating in a subcuticular suture of the skin.
Postoperatively, our patient displayed an adequate general status under antibiotic, anti-inflammatory and analgesic treatment. The patient received two units of transfused blood: one unit intraoperatively and another unit on the first postoperative day. Resumption of intestinal transit took place on the fifth postoperative day and micturition was deemed normal throughout her hospital stay. Prior to discharge, the patient underwent another transvaginal ultrasonography, which showed that the collection had successfully been evacuated from the Douglas pouch, as demonstrated in Figure 2. The patient's postoperative recovery was uneventful and she was discharged on the twelfth postoperative day.

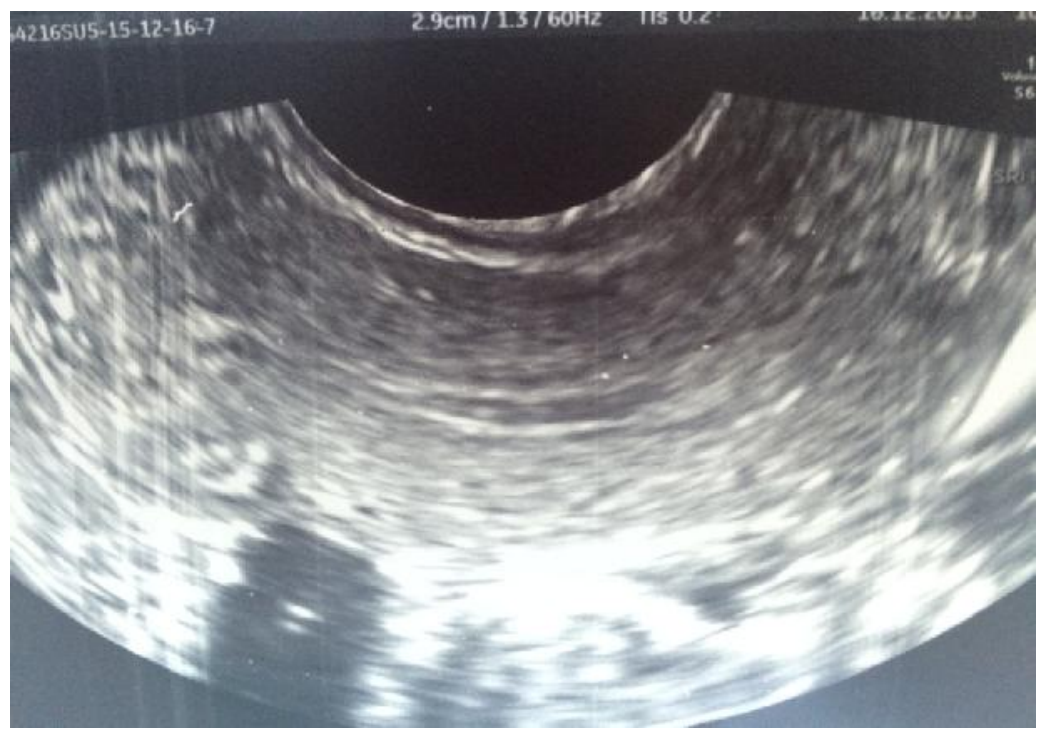

Figure 2: Evacuation of the collection in the Douglas pouch

Histopathological examination of the placenta confirmed the intraoperative diagnosis of placenta accreta, in addition to displaying areas of fibrinoid necrosis, vascular ectasia, haemorrhage and an acute inflammatory infiltrate. Microscopic examination of the left rudimentary hemi-uterus showed hypertrophied myometrial fibers dissociated by oedema and an acute inflammatory infiltrate.

\section{Discussion}

Although rare, primary uterine rupture is particularly morbid (Haidar et al., 2016, Sivanesan et al., 2010, Oral et al., 2001, Shirata et al., 2007, Hagnere et al., 2011, Abdalla et al., 2015, Surico et al., 2016, Sun et al., 2012, Vaknin et al., 2008, Ijaz et al., 2011). In addition to being a life-endangering event for both mother and fetus, complete uterine rupture culminating in peripartum hysterectomy is a most devastating outcome, particularly in a primigravida (Walsh et al., 2007, Akhtar, 2010).
The mechanism of rupture in this case was multifactorial, consisting of an interplay between four factors: the presence of a thin rudimentary uterine wall, which was further compromised by curettage, acute inflammation and abnormal placentation (placenta accreta). The already thin rudimentary wall was made friable by acute inflammation, while the invasive adherence of the placenta facilitated rupture in a uterus containing a weakened wall secondary to curettage. Moreover, the lack of follow-up after the D\&C left the defect undiagnosed.

The particularities of this case encompassed the lack of risk factors except for $\mathrm{D} \& \mathrm{C}$ and a congenital uterine anomaly, which was also undiagnosed, asymptomatic placenta accreta lacking ultrasonographic features and an unusual clinical presentation. Furthermore, literature describes the onset of abdominal pain in uterine rupture as sudden, however, in the presented patient, the pain debuted insidiously, a day prior to admission. 
Another peculiarity of the case was the abnormal placental adherence to the myometrium, which eliminated the possibility of preserving the left hemiuterus. The trigger was, however, the poor quality and weakened decidua, which was consumed by the placenta, in a tumour-like fashion.

The patient's clinical presentation at admission was characteristic of an acute abdomen requiring general surgical expertise, rather than uterine rupture, primarily due to the fact that the patient was unaware that she was pregnant, and secondarily, due to the lack of vaginal bleeding. Pregnancy was diagnosed after transabdominal ultrasound. The progressive haemoperitoneum was due to either an insidious uterine rupture, or chronic haemoperitoneum after an unrecognized perforation from the previous curettage.

In a recent literature review conducted by Surico D et. al, published in 2016, regarding the signs and symptoms of second trimester uterine ruptures, abdominal pain was present in 8 of the 9 cases $(88.9 \%)$ and none of the women presented with vaginal bleeding, as was the case of the presented patient (Surico et al., 2016). Their brief review reported three patients admitted in hypovolaemic shock, with haemoperitoneum ranging between 2000$3000 \mathrm{~mL}$.

Intra-abdominal bleeding is rare after the first trimester of pregnancy, during which the most common aetiology is ectopic pregnancy. Haemoperitoneum during the second trimester may be attributed to both obstetric and non-obstetric causes. The most frequent obstetric causes refer to invasive placentation, placental abruption, endometriosis and erosion of utero-ovarian vasculature. Emergency exploratory laparoscopy or laparotomy is required to establish a correct diagnosis of haemoperitoneum in pregnancy (Ijaz et al., 2011, Akhtar, 2010, Ble et al., 2011).
The congenital uterine anomaly at hand is a Class U4 hemi-uterus according to the ESHRE-ESGE 2013 Consensus on the Classification of Female Genital Tract Anomalies (Grimbizis et al., 2013). The uterine structure is described as a single uterus with two permeable hemi-uterine cavities, one of which is rudimentary, and a single cervix. On the initial transvaginal ultrasound, Uterus Didelphys was suspected as being the anomaly. Eleven weeks prior to presentation at the emergency room, when the patient underwent the $\mathrm{D} \& \mathrm{C}$ at another facility, the embryo was probably present in the left hemi-uterine cavity, while the right hemi-uterus was curetted, resulting in the cessation of menstruation and pregnancy continuation, which did not alarm the woman.

The inflammatory risks associated with $\mathrm{D} \& \mathrm{C}$ should not be neglected; however, it was not possible to prove them as a uterine culture was not harvested at admission.

Congenital uterine anomalies carry a prevalence of $4 \%$ to 7\% (Chan et al., 2011, Grimbizis et al., 2001, Saravelos et al., 2008). This miscellaneous category of benign uterine conditions is associated with early and recurrent pregnancy loss, malpresentation, intrauterine growth restriction and poor pregnancy outcomes such as preterm birth and intrauterine fetal death (Chan et al., 2011, Grimbizis et al., 2001, Saravelos et al., 2008, Hua et al., 2011), attributed to both anatomic and functional anomalies of the decidua and placenta (Hua et al., 2011).

This article reports the case of a spontaneous complete uterine rupture in a 17 -week primigravida with a rudimentary hemi-uterus and abnormal placental adherence. To the authors' knowledge, this is the third case in the world and the second case published since the new millennium of spontaneous complete uterine rupture during the second trimester in a primigravida with a congenital uterine anomaly, as demonstrated in Table 1 (Oral et al., 2001, Jones and Mitler, 1978, Damiani et al., 2013). 
Int. J. Curr. Res. Med. Sci. (2017). 3(1): 7-14

Table 1: Spontaneous Complete Primary Uterine Rupture During the Second Trimester in Women with a Congenital Uterine Anomaly

\begin{tabular}{|c|c|c|c|c|c|c|c|}
\hline Author & Year & Age & GA & Risk Factor(s) & $\begin{array}{c}\text { Initial } \\
\text { presentation }\end{array}$ & Procedure & Outcome \\
\hline $\begin{array}{c}\text { Jones } \\
\text { et al. }\end{array}$ & 1978 & 25 & 21 & $\begin{array}{c}\text { Bicornuate } \\
\text { uterus }\end{array}$ & $\begin{array}{c}\text { Abdominal } \\
\text { pain }\end{array}$ & Hysterectomy & $\begin{array}{c}\text { Fetal } \\
\text { death }\end{array}$ \\
\hline $\begin{array}{c}\text { Damiani } \\
\text { et al. }\end{array}$ & 2012 & 30 & 23 & D\&C & $\begin{array}{c}\text { Abdominal } \\
\text { pain }\end{array}$ & $\begin{array}{c}\text { Triple layer } \\
\text { hysterorrhaphy }\end{array}$ & $\begin{array}{c}\text { Fetal } \\
\text { death }\end{array}$ \\
\hline $\begin{array}{c}\text { Present } \\
\text { case }\end{array}$ & 2015 & 21 & 17 & $\begin{array}{c}\text { Rudimentary } \\
\text { hemi-uterus, } \\
\text { D\&C }\end{array}$ & $\begin{array}{c}\text { Abdominal } \\
\text { pain }\end{array}$ & Hemi-hysterectomy & $\begin{array}{c}\text { Fetal } \\
\text { death }\end{array}$ \\
\hline
\end{tabular}

The patient's prognosis is favorable from the perspective of fertility-conserving surgery, however, to date there is a complete paucity of literature on the topic of subsequent pregnancy outcome and delivery in patients with a congenital uterine anomaly who underwent a hemi-hysterectomy secondary to a complete uterine rupture. The authors are eagerly awaiting the return of this patient with a subsequent pregnancy.

This case demonstrates that clinical interpretation is often challenging without vaginal bleeding. Early correct diagnosis and prompt management are of the essence in order to decrease the astonishingly high rates of maternal and fetal morbidity and mortality associated with complete uterine rupture. Treatment depends, above all, on the extent of the lesion and gestational age, but also on parity, maternal age and the patient's future desire for fertility in addition to the surgeon's expertise (Surico et al., 2016). This case also highlights the importance of counseling and follow-up after D\&C.

The authors' message is to maintain a high index of suspicion of uterine rupture in every pregnant woman who presents with abdominal pain and signs of hypovolaemic shock, regardless of parity or gestational age.

\section{References}

1. Abdalla N, Reinholz-Jaskolska M, Bachanek M, Cendrowski K, Stanczak R, Sawicki W. 2015. Hemoperitoneum in a patient with spontaneous rupture of the posterior wall of an unscarred uterus in the second trimester of pregnancy. BMC Res Notes 8(1):603.

2. Akhtar Y. 2010. Ruptured uterus: an on-going tragedy of motherhood. Prof J Med 17(2):314-7.

3. Al-Zirqi I, Stray-Pedersen B, Forsén L, Daltveit AK, Vangen S. 2016. Uterine rupture: Trends over
40 years. BJOG An Int J Obstet Gynaecol. 123(5):780-7.

4. Ble R, Adjoussou S, Doukoure B. 2011. Placenta percreta: a rare etiology of spontaneous uterine perforation in the second trimester of pregnancy. Gynecol Obs Fertil 39:e11-4.

5. Chan YY, Jayaprakasan K, Zamora J, Thornton JG, Raine-Fenning N, Coomarasamy A. 2011.The prevalence of congenital uterine anomalies in unselected and high-risk populations: A systematic review. Hum Reprod Update 17(6):761-71.

6. Chen FP. 2007. Term delivery after repair of a uterine rupture during the second trimester in a previously unscarred uterus: a case report. J Reprod Med. 52(10):981-3.

7. Damiani GR, Gaetani M, Landi S, Lacerenza L, Barnaba M, Spellecchia D, et al. 2013. Uterine rupture in a nulliparous woman with septate uterus of the second trimester pregnancy and review in literature. Int J Surg Case Rep 22;4(3):259-61.

8. Gardeil F, Daly S, Turner MJ. 1994. Uterine rupture in pregnancy reviewed. Eur J Obs Gynecol Reprod Biol 56:107-10.

9. Gibbins KJ, Weber T, Holmgren CM, Porter TF, Varner MW, Manuck TA. 2015. Maternal and fetal morbidity associated with uterine rupture of the unscarred uterus. Am J Obstet Gynecol 213(3):382.e1-382.e6.

10. Grimbizis GF, Gordts S, Di Spiezio Sardo A, Brucker S, De Angelis C, Gergolet M, et al. 2013. The ESHRE-ESGE consensus on the classification of female genital tract congenital anomalies. Gynecol Surg 10(3):199-212.

11. Grimbizis, GF; Camus, M; Tarlatzis B et al. 2001. Clinical implications of uterine malformationsand hysteroscopic treatment results. Hum Reprod Updat 7(1):161-74. 
12. Guèye M, Mbaye M, Ndiaye-Guèye MD, KaneGuèye SM, Diouf AA, Niang MM, et al. 2012. Spontaneous Uterine Rupture of an Unscarred Uterus before Labour. Case Rep Obstet Gynecol 12: 1-3.

13. Hagnere P, Denoual I, Soussi A, Deswarte S. 2011. Spontaneous uterine rupture after myomectomy. Case report and review of the literature. J Gynecol Obs Biol Reprod 40:162-5.

14. Haidar ZA, Vowels PC, Moussa HN, Sibai BM. 2016. Successful Management of a Periviable Pregnancy with Morbidly Adherent Placenta after Uterine Rupture. J Obstet Gynaecol Canada 38(8):719-22.

15. Hofmeyr J, Say L, Gulmezoglu AM. 2005. WHO systematic review of maternal mortality and morbidity: the prevalence of uterine rupture. BJOG 112(9):1221-8.

16. Hua M, Odibo AO, Longman RE, MacOnes GA, Roehl KA, Cahill AG. 2011. Congenital uterine anomalies and adverse pregnancy outcomes. Am J Obstet Gynecol 205(6):558.e1-558.e5.

17. Ijaz S, Mahendru A, Sanderson D. 2011. Spontaneous uterine rupture during the 1st trimester: A rare but life-threatening emergency. J Obstet Gynaecol 31(8):772-772.

18. Jones D, Mitler L. 1978. Rupture of a gravid bicornuate uterus in a primigravida associated with clostridial and bacteroides infection. $\mathbf{J}$ Reprod Med 21:185-8.

19. Kabra SL, Laul P, Godha Z, Kadam VK. 2016. Case Series: Spontaneous Rupture of Uterus in Early Pregnancy. J Obstet Gynecol India 66 (S2):710-3.

20. Kawabe A, Wang L, Kikugawa A, Shibata Y, Kuromaki K. 2016.Taiwanese Journal of Obstetrics \& Gynecology Severe abdominal pain exacerbated by fetal movement is an early sign of the onset of uterine rupture. Taiwan J Obstet Gynecol 55(5):721-3.

21. Landon MB. Uterine rupture in primigravid women. 2006. Obstet Gynecol. 108 (No.3 Part 2):709-10.

22. Mazzone M, Woolever J. 2006. Uterine rupture in a patient with an unscarred uterus: a case study. Wis Med J 105:64-6.

23. Ofir K, Sheiner E, Levy A, Katz M, Mazor M. 2003. Uterine rupture: Risk factors and pregnancy outcome. Am J Obstet Gynecol 189(4):1042-6.

24. Oral B, Güney M, Özsoy M, Sönal S. 2001. Placenta accreta associated with a ruptured pregnant rudimentary uterine horn: Case report and review of the literature. Arch Gynecol Obstet 265(2):100-2.
25. Palacios-Jaraquemada JM, Fiorillo Á, Von Petery F, Colaci D, Leguizamón G. 2009. Uterine repair and successful pregnancy after myometrial and placental rupture with massive haemoperitoneum. BJOG An Int J Obstet Gynaecol 116(3):456-60.

26. Pepin M, Shwarze U, Superti-Furga A, Byers P. 2000. Clinical and Genetic Features of EhlersDanlos Syndrome Type IV, The Vascular Type. N Engl J Med 342(10):673-80.

27. Salama S, Nizard J, Camus E, Ville Y. 2009. Spontaneous haemoperitoneum after the second trimester of pregnancy. Diagnosis and management. Eur J Obstet Gynecol Reprod Biol 142(1):82-3.

28. Saravelos SH, Cocksedge KA, Li TC. 2008. Prevalence and diagnosis of congenital uterine anomalies in women with reproductive failure: A critical appraisal. Hum Reprod Update 14(5):41529.

29. Shirata I, Fujiwaki R, Takubo K, Shibukawa T, Sawada K. 2007. Successful continuation of pregnancy after repair of a midgestational uterine rupture with the use of a fibrin-coated collagen fleece (TachoComb) in a primigravid woman with no known risk factors. Am J Obstet Gynecol 197(4):7-9.

30. Sivanesan K, Singh M, Granger K. 2010. A case of ruptured uterus at 27 weeks of gestation complicated by placenta accreta. Arch Gynecol Obstet 282(1):107-9.

31. Sugawara T, Ogawa M, Tanaka T. 2014. Repair of uterine rupture during second trimester leading to successful pregnancy outcome: Case study and literature's review. Am J Perinatol Rep 4(1):9-12.

32. Sun HD, Su WH, Chang WH, Wen L, Huang BS, Wang PH. 2012. Rupture of a pregnant unscarred uterus in an early secondary trimester: A case report and brief review. J Obstet Gynaecol Res 38(2):442-5.

33. Surico D, Amadori R, Vigone A, D'Agostino C, Dessole M, Surico N. 2016. Successful delivery after surgical repair of uterine rupture at 15 weeks of gestation: case report and brief review. Eur $\mathbf{J}$ Obstet Gynecol Reprod Biol 204:5-8.

34. Thisted DLA, Mortensen LH, Krebs L. 2015. Uterine rupture without previous caesarean delivery: A population-based cohort study. Eur J Obstet Gynecol Reprod Biol 195:151-5.

35. Tola EN. 2014. Case Report First Trimester Spontaneous Uterine Rupture in a Young Woman with Uterine Anomaly. Case Rep Obstet Gynecol Article ID 967386: 3-6. http://dx.doi.org/10.1155/2014/967386 
36. Vaknin Z, Maymon R, Mendlovic S, Barel O, Herman A, Sherman D. 2008. Prenatal diagnosis of the Cockayne syndrome: survey of 15 years experience. Prenat Diagn 28:478-84.

37. Vernekar M, Rajib R. 2015. Unscarred Uterine Rupture: A Retrospective Analysis. J Obstet Gynecol India 66(1):51-4.

38. Walsh CA, Laxmi VB. 2007. Rupture of the primigravid uterus: a review of the literature. Obstet Gynecol Surv 62(5):327-34.

39. Yap OWS, Kim ES, Laros RK. 2001. Maternal and neonatal outcomes after uterine rupture in labor. Am J Obstet Gynecol 184(7):1576-81.

40. Zwart JJ, Richters JM, Öry F, De Vries JIP, Bloemenkamp KWM, Van Roosmalen J. 2009. Uterine rupture in the Netherlands: A nationwide population-based cohort study. BJOG An Int J Obstet Gynaecol 116(8):1069-78.

\begin{tabular}{|c|c|}
\hline \multicolumn{2}{|c|}{ Access this Article in Online } \\
\hline 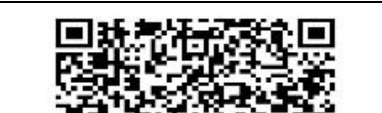 & $\begin{array}{l}\text { Website: } \\
\text { www.ijcrims.com }\end{array}$ \\
\hline 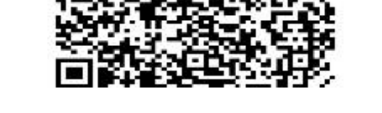 & $\begin{array}{l}\text { Subject: } \\
\text { Medicine }\end{array}$ \\
\hline Quick Response Code & \\
\hline
\end{tabular}

How to cite this article:

Samantha Mc Kenzie Stancu, Dragos Stefan Dobritoiu, Manuela Russu. (2017). "Insidious Spontaneous Complete Uterine Rupture in a 17-Week Primigravida with a Rudimentary Hemi-Uterus: A Case Report and Literature Review". Int. J. Curr. Res. Med. Sci. 3(1): 7-14.

DOI: http://dx.doi.org/10.22192/ijcrms.2017.03.01.002 